\title{
INTENSIDADE DA RAMULOSE SOB SEMEADURA CONVENCIONAL E DIRETA DO ALGODOEIRO $\left({ }^{1}\right)$
}

\author{
DANIELA KUBIAK DE SALVATIERRA $\left({ }^{2,5}\right)$; EDERALDO JOSÉ CHIAVEGATO $\left({ }^{3 *}\right)$; ARIANA VIEIRA E SILVA $\left({ }^{4,5}\right)$
}

\begin{abstract}
RESUMO
Foram realizados em Piracicaba (SP), em 2004/05 e 2005/06, experimentos com o algodoeiro (Gossypium hirsutum L. var. latifolium Hutch), sob preparo do solo e semeadura convencional; e ausência de preparo do solo com semeadura sobre palhada de milheto, com o objetivo de avaliar as modificações microclimáticas (temperatura e duração do período de molhamento-DPM), decorrentes da utilização da palhada de milheto, no desenvolvimento da ramulose (Colletotrichum gossypii South. var. cephalosporioides Costa) do algodoeiro. Foi utilizado também um índice de favorabilidade temperatura-molhamento (IF-tm) para a ramulose do algodoeiro, para avaliar o desenvolvimento da doença nos dois sistemas de semeadura. Os dados climáticos foram medidos por uma plataforma de aquisição de dados sob o dossel das plantas e na região central da área experimental. A ramulose foi avaliada por escala de notas ( 1 a 5$)$ e as médias das notas analisadas estatisticamente. Alterações no progresso da doença foram observadas, com ocorrência mais severa no sistema convencional de semeadura, porém não podendo ser atribuídas às variações na temperatura e DPM, consideradas isoladamente, mas decorrente de interações entre estas e a precipitação pluvial. O IF-tm teve boa relação com o aumento da severidade da doença, e a diferença, observada em maior proporção no sistema convencional de semeadura, ocorreu em períodos cujos valores de IF-tm foram altos, associados a períodos com chuvas e fase de maior suscetibilidade das plantas ao patógeno. Com IF-tm menores que 0,500 não se observa aumento efetivo da severidade da ramulose em quaisquer sistema de semeadura.
\end{abstract}

Palavras-chave: semeadura direta e convencional, algodoeiro, ramulose, microclima.

\section{ABSTRACT \\ RAMULOSIS INTENSITY UNDER CONVENTIONAL AND NO-TILLAGE COTTON CROP SYSTEMS}

During the years of 2004/05 and 2005/06, in Piracicaba, State of São Paulo, experiments were carried out with cotton crop under conventional tillage seeding and no-tillage. The seeding was performed over the mulching of millet, with the objective to evaluate if such mulching could interfere on temperature, leaf wetness duration (LWD) and development of ramulosis in cotton crop. It was also used the Favorability Index for the based on ramulosis cotton crop to explain the development differences of the disease the two seeding systems. Weather variables data were measured by an of acquisition data platform of the experimental area. The disease was measured by scales from 1 to 5 and the average was submitted to a statistic analysis. The difference on ramulosis severity between cotton crop under conventional tillage and conventional seeding was due to specific interactions for each period where many variables were involved (stage of the development of the plant and the macro and microclimatic conditions). The favorability index had a good relation with the increase of the ramulosis severity between both seeding systems. Ramulosis severity can be higher in conventional production system than in systems that uses mulching, particularly in periods when the index values are high: association of rain periods with crop susceptibility to the pathogen. When the index is lower than 0,500 effective increases on ramulosis severity is not observed in any seeding system.

Key words: no-tillage; cotton; ramulosis; microclimate.

(1) Parte do trabalho de tese de doutorado pela Universidade de São Paulo/Escola Superior de Agricultura "Luiz de Queiroz". Recebido para publicação em 31 de janeiro de 2008 e aceito em 12 de novembro de 2008.

$\left(^{2}\right)$ Doutoranda do Programa de Pós-Graduação em Fitotecnia da Universidade de São Paulo, Escola Superior de Agricultura "Luiz de Queiroz", Caixa Postal 9, 13418-900 Piracicaba (SP). E-mail: dmkubiak@hotmail.com

$\left({ }^{3}\right)$ Departamento de Produção Vegetal da Universidade de São Paulo, Escola Superior de Agricultura "Luiz de Queiroz". E-mail: ejchiave@esalq.usp.br $\left(^{*}\right)$ Autor correspondente.

$\left.{ }^{4}\right)$ Doutoranda do Programa de Pós-Graduação em Fitotecnia da Universidade de São Paulo/Escola Superior de Agricultura "Luiz de Queiroz", Piracicaba (SP). E-mail: ariana_otavio@hotmail.com.

$\left({ }^{5}\right)$ Bolsista CAPES. 


\section{INTRODUÇÃO}

Define-se como plantio direto a prática de semeadura ou cultivo de plantas sem o preparo físico do solo, mantendo a palha ou cobertura da cultura anterior na superfície do solo, e rotação de culturas (GASSEN e GASSEN, 1996). Nesse sistema de produção, a cobertura permanente e os resíduos de plantas podem afetar a temperatura e a umidade na superfície do solo (Benoit e Lindstrom, 1987, Adams, 1966; Fowler e RocKSTROM, 2001) e contribuir para a modificação na temperatura em nível microclimático, alterar as condições de umidade, ou o tempo em que a película de água proveniente de orvalho, chuva ou irrigação permanece sobre as folhas, alterando a duração do período de molhamento foliar (DPM) (Rotem, 1978; Pedro Júnior et al., 1991).

Diferentes patógenos de plantas necessitam de condições distintas ou horas de molhamento foliar em conjunto com a temperatura para que possam infectar e colonizar o hospedeiro. Horsford et al. (1987) e Allen et al. (1982) afirmam que para a maioria dos patógenos são necessárias pelo menos entre 2 a 6 horas de molhamento para iniciar a infecção, e poucos são desfavorecidos pela presença da água, necessitando apenas de alta umidade relativa para iniciarem seu desenvolvimento. Segundo Rotem (1978) e ZADOCKs e Schein (1979), em condições de temperatura desfavorável para o desenvolvimento do patógeno, a taxa de progresso da doença pode ser reduzida. Quanto às práticas culturais, BATSON JR e CACERES (2000), constataram que as doenças de plântulas são geralmente mais severas sob condições de preparo reduzido e plantio direto, e que o vigor das plantas é menor, podendo consequentemente, diminuir a produtividade.

O algodoeiro é reconhecido como hospedeiro de grande número de patógenos. Quando cultivado em sistemas conservacionistas, fato comum é a ocorrência de tombamento de plântulas já relatado por vários autores como KAUfMAN e WHEELER (1995); YounG (1995) e Sumner et al. (1995). Porém, segundo Cia e FuzATTO (1999) essa ocorrência pode ser minimizada com a utilização de rotação de culturas.

No Brasil, a ramulose do algodoeiro, cujo agente causal é o fungo Colletotrichum gossypii South. var. cephalosporioides Costa, é uma das principais doenças que ocorre nas diversas regiões produtoras, cujo comportamento em sistemas conservacionistas, como o plantio direto, cultivo mínimo ou semeadura na palha, ainda é pouco estudado.

Nas principais regiões produtoras de algodão no Brasil, o milheto (Pennisetum glaucum L.) tem sido amplamente utilizado como cobertura para formação de palhada. Segundo ZANDONADI (2005), proporciona excelente cobertura do solo $(90 \%)$ com 8 a $10 \mathrm{tha}^{-1}$ de matéria seca.

Kubiak (2003), estudando a influência da palhada de milheto no comportamento e progresso da ramulose, observou que a doença ocorreu de forma mais severa no sistema de semeadura convencional do que naquele com utilização de milheto, porém, avaliando somente as condições proporcionadas em nível macroclimático.

Assim, este estudo teve por objetivo verificar as interferências no progresso da ramulose por meio de alterações microclimáticas (temperatura e duração do período de molhamento foliar) sob o dossel da cultura do algodoeiro, comparativamente na ausência de preparo físico do solo com palhada de milheto na superfície, e preparo convencional do solo, sem utilização de cobertura.

\section{MATERIAL E MÉTODOS}

Dois experimentos foram desenvolvidos nos anos agrícolas de 2004/2005 e 2005/2006, em área experimental da Escola Superior de Agricultura "Luiz de Queiroz", Piracicaba (SP). O clima da região é Cwa (mesotérmico, úmido, subtropical com inverno seco), segundo classificação de Köppen (Vianello e Alves, 1991).

Para as avaliações propostas, dois sistemas de produção foram utilizados: semeadura convencional (SC), que compreendeu a semeadura do algodoeiro em solo preparado de maneira convencional e semeadura direta (SD) sobre palhada de milheto e ausência de preparo físico do solo. Este último, por compreender apenas dois anos de manejo e pela ausência de rotação de culturas, não se constitui o clássico sistema de plantio direto.

Foi utilizada a cultivar de algodoeiro Makina, semiprecoce, com ciclo de aproximadamente 160 dias e considerada suscetível a várias doenças causadas por fungos, com destaque à ramulose, doença fúngica de interesse nesta pesquisa. As semeaduras foram realizadas em $22 / 11 / 2004$ e 17/11/2005, respectivamente, no primeiro e segundo ano de experimentação.

Para a formação de palhada sobre a superfície do solo, foi utilizado o milheto (Pennisetum glaucum L.), cultivar BN-2, comumente utilizado em sistemas de plantio direto no Brasil. As semeaduras ocorreram em 3/9/2004 no primeiro ano e 16/9/2005 no segundo ano, respectivamente, aos 81 e 63 dias antes da semeadura do algodoeiro. Para garantia da germinação e produção de massa seca, o manejo da 
área experimental foi realizado sob irrigação por aspersão. A dessecação do milheto foi efetuada com o herbicida Glifosato, na dose de $4 \mathrm{~L} \mathrm{ha}^{-1}, 10$ dias antes da semeadura do algodoeiro.

O delineamento experimental adotado foi em parcelas subdivididas com oito repetições, constando de quatro blocos alternados, sendo dois deles com preparo do solo convencional (uma aração e duas gradagens) e mantido livre de cobertura superficial, e dois blocos sem preparo físico do solo e semeadura de milheto a lanço. As subparcelas constaram de quatro linhas de $5 \mathrm{~m}$, com espaçamento nas entrelinhas de $0,9 \mathrm{~m}$, distribuídas nos blocos com e sem palhada. O ajuste do estande foi realizado aos 30 dias após a semeadura, permanecendo 10 plantas por metro linear.

Os tratamentos com e sem inoculação das plantas de algodoeiro com Colletotrichum gossypii South. var. cephalosporioides Costa, compreenderam: semeadura direta inoculada (T1); semeadura direta não inoculada (T2), semeadura convencional inoculada (T3) e semeadura convencional não inoculada (T4).

A cultura do algodoeiro foi mantida livre de plantas daninhas, por meio de herbicidas e capinas manuais. Nas subparcelas com palhada de milheto, o controle da rebrota do algodoeiro, remanescente do ano anterior, foi realizado com o herbicida Glifosato, na dose de $4 \mathrm{~L} \mathrm{ha}^{-1}$. O adubo utilizado na semeadura foi o formulado 4-25-25, na quantidade de $350 \mathrm{~kg} \mathrm{ha}^{-}$ ${ }^{1}$. Na adubação de cobertura foi utilizado $90 \mathrm{~kg} \mathrm{ha}^{-1}$ de N.

O manejo fitossanitário foi realizado por meio de pulverizações semanais, sendo o bicudo do algodoeiro (Anthonomus grandis L.) o alvo principal. Outros insetos, com ocorrência esporádica, foram controlados tais como: pulgões (Aphis gossypii Glover), tripes (Frankliniela sp.), ácaros (Polyphagotarsonemus latus Banks e Tetranichus urticeae), curuquerê do algodoeiro (Alabama argillaceae) e outras lagartas.

Duas colheitas do algodão foram realizadas manualmente, em ambos os anos, iniciando-se quando atingido $80 \%$ de capulhos nas plantas.

A inoculação das plantas com Colletotrichum gossypii South. var. cephalosporioides Costa foi realizada a partir de uma mistura de cinco isolados, com as culturas desenvolvidas em meio sólido em placa de Petri e a suspensão preparada após o período de incubação.

Para o preparo da suspensão do inóculo, foram adicionados $15 \mathrm{~mL}$ de água destilada em cada placa de Petri contendo a cultura do fungo, sendo removida a parte superficial da colônia com auxilio de espátula. Ao material resultante (água e fungo), foi adicionado água destilada, completando-se o volume para 2 litros. Em seguida, a suspensão foi filtrada em duas camadas de gaze, obtendo-se a concentração de $1 \times 10^{6}$ conídios $\mathrm{mL}^{-1}$. Esta suspensão foi aplicada sobre as plantas de algodoeiro com pulverizador costal com bico $\mathrm{X}_{2}$ e dotado de $\mathrm{CO}_{2}$, com pressão constante de 42 libras pol$^{-1}$. As inoculações foram realizadas aos 30 e 40 dias após a emergência das plantas em 2004/2005 e 2005/2006 respectivamente, sempre ao fim da tarde, evitando-se a incidência de radiação solar e sob temperaturas amenas, a fim de favorecer o processo infeccioso. As aplicações foram concentradas na região apical das plantas.

O progresso da doença foi avaliado a cada 7 dias, após as inoculações, por meio de escala de notas de 1 a 5 (1 - planta sem sintomas visíveis; 2 - planta com manchas estreladas nas folhas do ponteiro; 3 planta com redução nos internódios do ponteiro e manchas nas folhas; 4 - planta com superbrotamento, com pouca diminuição no crescimento e 5. planta com superbrotamento e com desenvolvimento e porte reduzido), descrita por CiA et al. (1982), em cinco plantas marcadas em cada parcela e sua planta imediatamente adjacente, totalizando 10 plantas por subparcela.

Para avaliar o progresso da doença nos dois sistemas de semeadura, as médias das notas, atribuídas aos sintomas de ramulose, foram submetidas à análise de variância. Considerando que os dados não tiveram distribuição normal, foram utilizados os testes não paramétricos: Teste de Kruskal-Wallis e Teste de U de Mann-Whitney.

As variáveis climáticas foram tomadas por meio de uma plataforma de aquisição de dados relativos às condições meteorológicas gerais (macroclimáticas) durante o ciclo da cultura, instalada na região central da área experimental. Foram instalados, também, conjunto-sensores - próximo à plataforma - com psicrômetros aspirados e um sensor eletrônico de molhamento, possibilitando o registro dos dados relativos à temperatura e umidade relativa do ar sob o dossel das plantas. O sensor eletrônico de molhamento foliar possibilitou o registro da duração do período de molhamento (DPM), ou seja, o período durante o qual havia água líquida na superfície das plantas (e do sensor) seja por deposição de orvalho seja por água de chuva. O conjunto sensor foi fixado nas entrelinhas das linhas centrais (úteis) das subparcelas. A altura dos sensores foi frequentemente ajustada, acompanhando o crescimento da cultura, de forma a mantê-los na altura do terço superior das plantas. 
Para elucidar possíveis diferenças ocorridas no desenvolvimento da ramulose entre os dois sistemas de semeadura, foi determinado também o índice de favorabilidade temperatura-molhamento para a ramulose (IF-tm), desenvolvido por MONTEIRO (2007), que utiliza no seu cálculo os dados de temperatura e molhamento obtidos em nível microclimático na área experimental.

Este método utiliza os parâmetros "a", "b" e " $c$ ", determinados por meio de equações de ajuste que descrevem suas relações com a temperatura.

As equações deste modelo exponencial para determinar o IF-tm para a ramulose em função da temperatura e molhamento que melhor se ajustaram aos dados de progresso da ramulose foram:

$$
\left.\mathbb{F} \text { tm }=\mathrm{a} \times 10^{-0,5}\left[\left(\frac{\mathrm{Ln}\left(\frac{\mathrm{DPM}}{\mathrm{b}}\right)}{\mathrm{c}}\right)^{2}\right]\right\}
$$

onde

$$
\begin{aligned}
& a=\left\{\frac{1,02}{1+e[(15,9-\mathrm{T}) / 0,9]}\right\} \times\left\{1-\frac{1}{\left.\left.1+e^{(T-33,5) / 2,1]}\right]\right\}}\right. \\
& b=-0,0078 T^{3}+0,768 T^{2}-26,98 T+353 \\
& c=-0,001 T^{2}+0,043 T+0,4984
\end{aligned}
$$

Assim, a partir dos dados obtidos de temperatura (T) e DPM no monitoramento microclimático, por substituição nas equações acima, obteve-se o IF-tm para cada período.

\section{RESULTADOS E DISCUSSÃO}

No ano agrícola de 2004/2005, a partir da análise das notas médias atribuídas à ramulose (Tabela 1), pode-se observar diferenças significativas na severidade da doença entre os tratamentos durante o ciclo da cultura. Relevantes para esse estudo são as comparações entre os tratamentos T1 (semeadura direta com inoculação) e T3 (semeadura convencional com inoculação). Entre esses dois tratamentos, apenas no período compreendido entre 57 e 64 DAE, respectivamente, aos 27 e 34 dias após a inoculação, foram observadas diferenças significativas no progresso da doença, com ocorrência mais severa nas plantas sob semeadura convencional, como pode ser visualizado na figura 1 . Em estudos anteriores, SANTOS et al. (1993) e CiA e SALGADO (2005), relataram que as fases mais suscetíveis do algodoeiro ao patógeno, correspondem ao período entre 25 e $45 \mathrm{DAE}$, período em que foram realizadas as inoculações no presente estudo. Esses autores salientam que a pré-disposição do hospedeiro decresce ao longo do ciclo e, segundo ABRAHÃo (1949), quando a doença, ocorre nas fases mais avançadas de desenvolvimento das plantas, chamada ramulose tardia, são menores os prejuízos à produção e à qualidade da fibra.

Quanto à maior severidade da ramulose observada na semeadura convencional, KUBIAK (2003) obteve resultados semelhantes no ano agrícola de 2001/2002, comparando também os dois sistemas de semeadura.

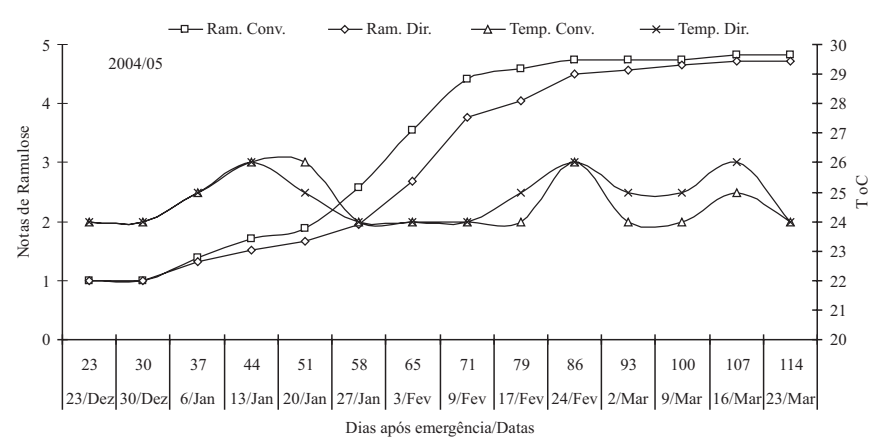

Figura 1. Progresso de severidade de ramulose e temperatura média do ar, em períodos de 7 dias, nos dois sistemas de semeadura (convencional e direta), dos 23 aos 114 dias após emergência (DAE), no ano

\begin{tabular}{|c|c|c|c|c|c|c|c|c|c|c|c|c|c|}
\hline Datas & $23 / \mathrm{dez}$ & $30 / \mathrm{dez}$ & 6/jan & 13/jan & $20 /$ jan & $27 /$ jan & $2 / \mathrm{fev}$ & $10 /$ fev & $17 /$ fev & $24 / \mathrm{fev}$ & $3 / \mathrm{mar}$ & $10 /$ mar & $17 / \mathrm{mar}$ \\
\hline DAE & 30 & 36 & 43 & 50 & 57 & 64 & 70 & 78 & 85 & 92 & 100 & 107 & 114 \\
\hline $\mathrm{T} 1 \times \mathrm{T} 2$ & 1 & $0,005^{*}$ & $<0,001^{*}$ & $<0,001^{*}$ & $<0,001^{*}$ & $<0,001^{*}$ & $<0,001^{*}$ & $<0,001^{*}$ & $<0,001^{*}$ & $<0,001^{*}$ & $<0,001^{*}$ & $<0,001^{*}$ & $<0,001^{*}$ \\
\hline T1xT3 & 0,153 & 0,49 & 0,524 & 0,157 & $0,016^{*}$ & $0,04^{*}$ & 0,075 & 0,142 & 0,687 & 0,687 & 1 & 0,655 & 0,655 \\
\hline $\mathrm{T} 1 \times \mathrm{T} 4$ & 1 & $0,005^{*}$ & $0,005^{*}$ & $<0,001^{*}$ & $<0,001^{*}$ & $<0,001^{*}$ & $<0,001^{*}$ & $<0,001^{*}$ & $<0,001^{*}$ & $<0,001^{*}$ & $<0,001^{*}$ & $<0,001^{*}$ & $<0,001^{*}$ \\
\hline $\mathrm{T} 2 \times \mathrm{T} 3$ & 0,153 & $0,001^{*}$ & $<0,001^{*}$ & $<0,001^{*}$ & $<0,001^{*}$ & $<0,001^{*}$ & $<0,001^{*}$ & $<0,001^{*}$ & $<0,001^{*}$ & $<0,001^{*}$ & $<0,001^{*}$ & $<0,001^{*}$ & $<0,001^{*}$ \\
\hline $\mathrm{T} 2 \times \mathrm{T} 4$ & 1 & 1 & 1 & 1 & 1 & 0,317 & 1 & 0,153 & $0,039 *$ & $0,039^{*}$ & $0,039^{*}$ & $0,039^{*}$ & $0,039^{*}$ \\
\hline T3xT4 & 0,153 & $0,001^{*}$ & $<0,001^{*}$ & $<0,001^{*}$ & $<0,001^{*}$ & $<0,001^{*}$ & $<0,001^{*}$ & $<0,001^{*}$ & $<0,001^{*}$ & $<0,001^{*}$ & $<0,001^{*}$ & $<0,001^{*}$ & $<0,001^{*}$ \\
\hline
\end{tabular}
agrícola 2004/2005, em Piracicaba (SP).

Tabela 1. Comparação entre os tratamentos: semeadura direta inoculada (T1); semeadura direta não inoculada (T2), semeadura convencional inoculada (T3) e semeadura convencional não inoculada (T4). 2004/2005

* Interação significativa a 0,05\%, pelo teste de Mann-Whitney para cada avaliação entre os tratamentos 
Ainda com relação ao período de maior severidade da doença (57 a $64 \mathrm{DAE}$ ), observa-se na figura 1 que a temperatura variou nesse período, entre 24 e $25{ }^{\circ} \mathrm{C}$ indistintamente nos dois sistemas, condições favoráveis à ocorrência da ramulose como já relatado por SANTOS et al. (1993) e Cia e SALGADO (2005). Portanto, a temperatura isoladamente não pode ser a única variável responsável pela maior severidade da doença no sistema em semeadura convencional.

Em relação à DPM, medida durante o ciclo da cultura, foi muito semelhante nos dois sistemas de semeadura como se observa na figura 2 . No período entre 57 e 64 DAE, pode-se constatar que as maiores médias de DPM foram atingidas ao redor de 20 horas, semelhante nos dois sistemas de semeadura. Porém, embora alta, e favorável ao progresso da epidemia como salientam Rotem (1978) e Pedro Júnior et al. (1991), analisando-se isoladamente a DPM nesse ano, as diferenças de severidade da doença ocorridas entre os dois sistemas estudados não pode ser explicada em função apenas dessa variável.

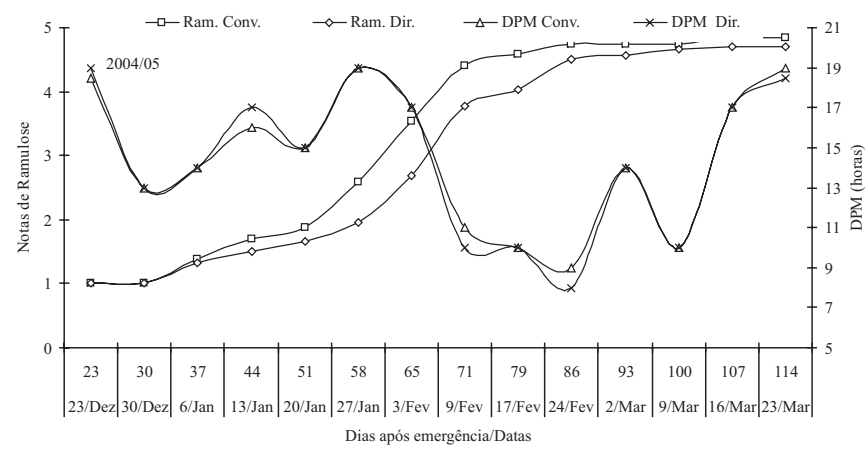

Figura 2. Progresso de severidade de ramulose e duração do período de molhamento (DPM), em períodos de 7 dias, nos dois sistemas de semeadura (convencional e direta), dos 23 aos 114 dias após emergência (DAE), no ano agrícola 2004/2005, em Piracicaba (SP).

Para o IF-tm calculado por meio dos dados de temperatura e DPM, observa-se na figura 3 que, no período de 57 a 64 dias, com este índice ocorreram os valores mais elevados, sendo maiores no sistema convencional de semeadura. Pode-se, assim, ajudar a explicar a diferença na severidade da doença observada entre os dois sistemas de semeadura.

Confrontando esses dados com a ocorrência de chuvas registradas durante o ciclo da cultura (Figura 4), observa-se que o período de 50 a 55 DAE foi chuvoso. Consequentemente, pode colaborar no agravamento da infecção, pois, é positiva a correlação do desenvolvimento de doenças com o número de dias chuvosos e a intensidade da chuva, como relatado em estudos de previsão de doenças (KUMAR et al., 1998; ChaKRABORTY e Billard, 1995).

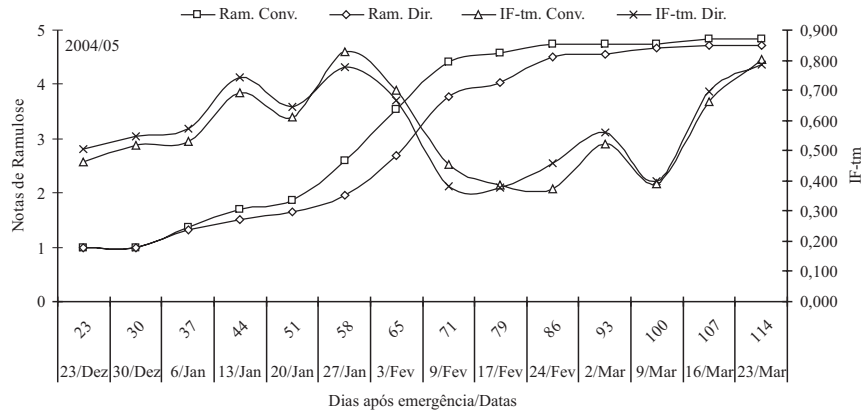

Figura 3. Progresso de severidade de ramulose e índice de favorabilidade temperatura-molhamento foliar (IFtm), em períodos de 7 dias, nos dois sistemas de semeadura (convencional e direta), dos 23 aos 114 dias após emergência (DAE), no ano agrícola 2004/2005, em Piracicaba (SP).

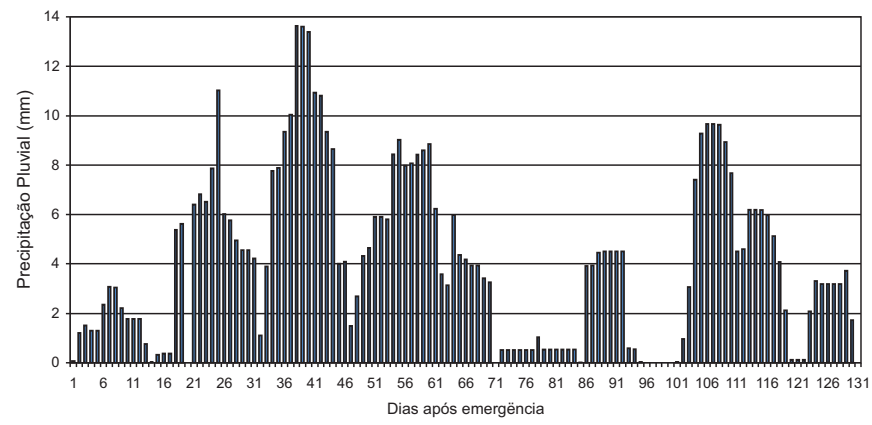

Figura 4. Precipitação pluvial (mm) no período de 1 a 131 dias após emergência (DAE), no ano agrícola 2004/ 2005, em Piracicaba (SP).

Com respeito aos demais tratamentos, embora se observem interações significativas entre os tratamentos T2 e T4 (semeadura direta e semeadura convencional sem inoculação) a partir dos 85 DAE, tal fato pode ser resultante de uma provável disseminação do inóculo na área a partir dos tratamentos submetidos à inoculação.

No segundo ano de experimentação (2005/ 2006), não foram observadas diferenças significativas nas médias das notas para ramulose entre os dois sistemas de semeadura, particularmente em nenhum período durante o ciclo da cultura (Tabela 2). A severidade da doença nesse ano ocorreu de forma mais branda, sendo muito semelhante entre SC e SD até $85 \mathrm{DAE}$ das plantas.

Em 2005/2006, as médias de temperatura em nível microclimático foram mais amenas que no ano anterior (Figura 5). Nota-se que a partir de $41 \mathrm{DAE}$, quando a temperatura começou a subir, atingindo cerca de $25^{\circ} \mathrm{C}$ aos $54 \mathrm{DAE}$, coincide com o progresso contínuo inicial da doença, sendo este menos intenso quando as médias de temperatura começaram a abaixar. 
Tabela 2. Comparação entre os tratamentos: semeadura direta inoculada (T1); semeadura direta não inoculada (T2), semeadura convencional inoculada (T3) e semeadura convencional não inoculada (T4). 2005/2006

\begin{tabular}{lcccccccccccc}
\hline Datas & $6 /$ jan & $13 /$ jan & $19 /$ jan & $26 /$ jan & $2 / \mathrm{fev}$ & $9 / \mathrm{fev}$ & $16 / \mathrm{fev}$ & $23 / \mathrm{fev}$ & $2 / \mathrm{mar}$ & $9 / \mathrm{mar}$ & $16 / \mathrm{mar}$ \\
DAE & 41 & 48 & 54 & 61 & 68 & 75 & 82 & 89 & 96 & 103 & 110 \\
\hline T1xT2 & 1 & $<0,001^{*}$ & $<0,001^{*}$ & $<0,001^{*}$ & $<0,001^{*}$ & $<0,001^{*}$ & $<0,001^{*}$ & $<0,001^{*}$ & $<0,001^{*}$ & $<0,001^{*}$ & $<0,001^{*}$ \\
T1xT3 & 1 & 0,146 & 0,909 & 0,966 & 0,823 & 0,668 & 0,526 & 0,39 & 0,324 & 0,143 & 0,143 \\
T1xT4 & 1 & $<0,001^{*}$ & $<0,001^{*}$ & $<0,001^{*}$ & $<0,001^{*}$ & $<0,001^{*}$ & $<0,001^{*}$ & $<0,001^{*}$ & $<0,001^{*}$ & $<0,001^{*}$ & $<0,001^{*}$ \\
T2xT3 & 1 & 0,011 & $<0,001^{*}$ & $<0,001^{*}$ & $<0,001^{*}$ & $<0,001^{*}$ & $<0,001^{*}$ & $<0,001^{*}$ & $<0,001^{*}$ & $<0,001^{*}$ & $<0,001^{*}$ \\
T2xT4 & 1 & 1 & 1 & 1 & 1 & 1 & 1 & 1 & 1 & 1 \\
T3xT4 & 1 & 0,011 & $<0,001^{*}$ & $<0,001^{*}$ & $<0,001^{*}$ & $<0,001^{*}$ & $<0,001^{*}$ & $<0,001^{*}$ & $<0,001^{*}<0,001^{*}<0,001^{*}$ \\
\hline
\end{tabular}

* Interação significativa a 0,05\%, pelo teste de Mann-Whitney para cada avaliação entre os tratamentos.

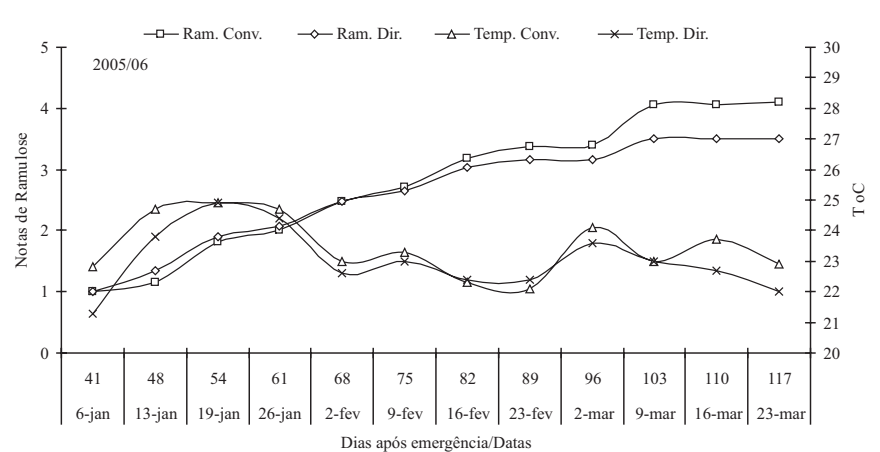

Figura 5. Progresso de severidade de ramulose e temperatura média do ar, em períodos de 7 dias, nos dois sistemas de semeadura (convencional e direta), dos 41 aos 117 dias após emergência (DAE), no ano agrícola 2005/2006, em Piracicaba (SP).

Em relação à DPM, embora decrescendo desde os $41 \mathrm{DAE}$, em ambos os sistemas de semeadura, a média de horas de molhamento foliar, proporcionou condições favoráveis para a ocorrência de infecção (Figura 6). MonTEIRo (2007), também trabalhando com a ramulose, constatou que o período de molhamento mínimo necessário para que ocorra infecção, diminuiu com o aumento da temperatura, sendo de 4 horas em temperaturas iguais ou maiores que $25^{\circ} \mathrm{C}, 8$ horas a $20^{\circ} \mathrm{C}$ e 17 horas a $15^{\circ} \mathrm{C}$. Ainda, acrescenta-se que a intensidade aumenta com a DPM, de 0 à 34 horas. Assim, considerada isoladamente, a DPM foi favorável ao desenvolvimento da ramulose em todos os períodos do ciclo, nos dois sistemas de semeadura estudados.

Para o IF-tm, as médias foram inferiores às do ano anterior durante todo o ciclo da cultura, além de mais instável, com o máximo de 0,600 , observado apenas aos 100 DAE (Figura 7).

Esse fato pode ajudar a explicar a menor severidade da doença nesse ano, embora houvesse temperatura e DPM favoráveis à ocorrência da doença, se consideradas essas variáveis isoladamente.

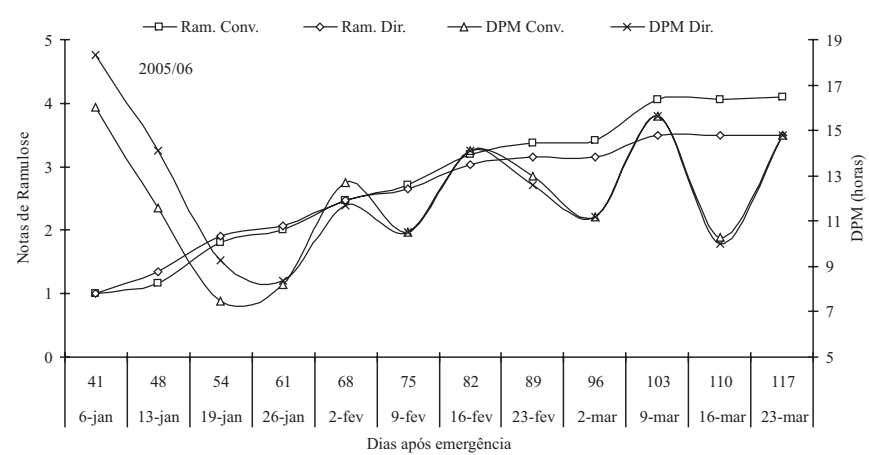

Figura 6. Progresso de severidade de ramulose e duração do período de molhamento (DPM) em períodos de 7 dias, nos dois sistemas de semeadura (convencional e direta), dos 41 aos 117 dias após emergência (DAE), no ano agrícola 2005/2006, em Piracicaba (SP).

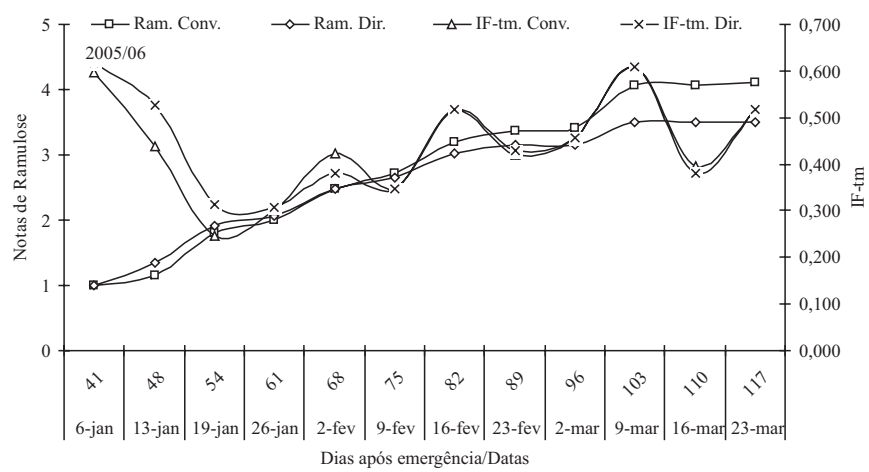

Figura 7. Progresso de severidade de ramulose e índice de favorabilidade temperatura-molhamento foliar (IFtm), em períodos de 7 dias, nos dois sistemas de semeadura (convencional e direta), dos 41 aos 117 dias após emergência (DAE), no ano agrícola 2005/2006, em Piracicaba (SP).

\section{CONCLUSÕES}

1. Não foi possível relacionar temperatura e duração do período de molhamento (DPM), se consideradas isoladamente, com o aumento da severidade da ramulose nos dois sistemas de semeadura. 
2. O índice de favorabilidade temperaturamolhamento (IF-tm) teve boa relação com o aumento da severidade da ramulose e com as diferenças ocorridas na severidade desta entre os dois sistemas de semeadura.

3. Pode ocorrer maior severidade da ramulose em sistema convencional de semeadura, em maior proporção do que nos sistemas com utilização de palhada na superfície do solo, em períodos quando os valores de IF-tm são altos, associados a períodos com chuvas e fase de maior suscetibilidade das plantas ao patógeno. Com índices de favorabilidade temperatura-molhamento menores que 0,500 , não se observa aumento efetivo da severidade da ramulose em quaisquer sistema de semeadura.

\section{AGRADECIMENTOS}

À Fundação Coordenação de Aperfeiçoamento de Pessoal de Nível Superior CAPES, pela concessão da bolsa de doutorado à primeira autora. À Escola Superior de Agricultura "Luiz de Queiroz" - Universidade de São Paulo e ao Centro de Análise e Pesquisa Tecnológica do Agronegócio de Grãos e Fibras - Instituto Agronômico / Agência Paulista de Tecnologia dos Agronegócios, pela cessão do inóculo.

\section{REFERÊNCIAS}

ABRAHÃO, J.; COSTA, A.S. Instruções para o reconhecimento da ramulose do algodoeiro. O Biológico, São Paulo, v.15, n.3, p.59-60. 1949.

ADAMS, J. E. Influence of mulches on runoff, erosion and soil moisture depletion. Soil Science Society of America Proceedings, Madison, v.30, p110-114, 1966.

ALLEN, S. J.; BROWN, J. F.; KOCHMAN, J. K. Effect of temperature, dew period, and light on the growth and development of Alternaria helianthi. Phytopathology, Saint Paul, v. 73, p. 793-796, 1982.

BATSON, JR., W. E.; CACERES, J. Evaluation seegling disease control strategies for cotton planted in conventional and stale bed tillage systems. In: BELTWIDE COTTON CONFERENCE, 2000, Orlando. Proceedings... Memphis: National Cotton Council of América, 2000.

BENOIT, G. R.; LINDSTROM, M. J. Interpreting tillage-residue management effects. Journal of Soil and Water Conservation, Ankeny, v. 1, p. 87-90, 1987.

CHAKRABORTY, S.; BILLARD, L. Quantitative relationships between Colletotrichun gloeosporioides infection of Stylosantes scabra and weather under field condition. Plant Pathology, New York, Reading, v. 44, p. 63-72, 1995.
CIA, E.; FUZATTO, M. G.; GRIDI-PAPP, I. L.;SOAVE, J.; CIONE, J. Avaliação da incidência de Ramulose do algodoeiro através de inoculação artificial. In: REUNIÃO NACIONAL DO ALGODÃO, 2., 1982, Salvador. Resumos... Campina Grande, EMBRAPA-CNPA, 1982. p. 241.

CIA, E.; FUZATTO, M. G.; Manejo de doenças na cultura do algodoeiro no Brasil. In: CIA, E.; FREIRE, E. C.; SANTOS, W. J. (Ed.). Cultura do Algodoeiro. Piracicaba: Potafós, 1999. p. 121131.

CIA, E.; SALGADO, C. L. Doenças do Algodoeiro. In: Manual de Fitopatologia. São Paulo: Ceres, 2005. p. 41-52

FOWLER, R.; ROCKSTROM, J. Conservation tillage for sustainable agriculture; $\mathrm{Na}$ agrarian revolution gathers momentum in Africa. Soil and Tillage Research, Amsterdam, v. 61, p. 93-107, 2001.

GASSEN, D.; GASSEN, F. Plantio direto, o caminho do futuro: Teoria e princípios sobre plantio direto. 2.ed. Passo Fundo: Aldeia Sul, 1996. cap. 1, p. 19-26.

HOSFORD, R. M.; LAREZ, C. R.; HAMMOND, J. J. Interaction of wet period and temperature on Pyrenophora tritici-repentis infection and development in wheats of differing resistance. Phytopathology, St. Paul, v. 77, n. 7, p. 1021-1027, 1987.

KAUFMAN, H. W.; WHEELER, T. A. et al. Conservation tillage practices in texas and their effects on seedling disease severity. In: BELTWIDE COTTON CONFERENCE, 1995, San Antonio. Proceedings... Memphis: National Cotton Council of America, 1995. v.1, p. 204.

KUBIAK, D.M. Influência da palhada de milheto na ocorrência de ramulose (Colletotrichum gossypii var. cephalosporioides Costa) no algodoeiro. Piracicaba:ESALQ-USP, 2003. 68p. Dissertação (Mestrado). ESALQ/USP. Piracicaba.

KUMAR, A.; SATYAVIR; NIWAS, R. Prediction of red rot Colletotrichum falcatum incidence in sugarcane under field conditions using climatic variables. In: INTERNATIONAL CONGRESS OF PHYTOPATHOLOGY, 7., 1998, Edinburgh. Abstract... Edinburg: Academic Press, 1998. p. 333-335.

MONTEIRO, J.E.B.A. Índice de favorabilidade agrometeorológica da ramulose (Colletotrichum gossypii pv. cephalosporioides) e da mancha angular (Xanthomonas axonopodis pv. malvacearum) do algodoeiro. Piracicaba, 2007. 109p. Tese (Doutorado em Física do ambiente agrícola) - Escola Superior de Agricultura Luiz de Queiroz, Universidade de São Paulo, Piracicaba, 2007.

PEDRO JÚNIOR, M.J.; PEZZOPANE, J.E.M.; ALFONSI, R.R.; MARTINS, F.P. Duração do período de molhamento em videira. In: CONGRESSO BRASILEIRO DE AGROMETEOROLOGIA, 7., 1991, Viçosa. Resumos...Viçosa: UFV; SBA, 1991. p. 151-153.

ROTEM, J. Climatic and weather influences on epidemics. In: HORSFAL, J.G.; COWLING, E.B. (Ed.). Plant disease: An advanced treatise. New York: Academic Press, 1978. v. 2, p. 317-334. 
SANTOS, G. R. Progresso da Ramulose do algodoeiro e transmissão de Colletotrichum gossypii South. var. cephalosporioides Costa pelas sementes. 1993.53p. Dissertação (Mestrado na área de Patologia de Sementes) - Universidade Federal de Viçosa, Viçosa, 1993.

SANTOS, G. R.; ZAMBOLIM, L.; BATISTA, U. G. Transmissão de Colletotrichum Gossypii var. cephalosporioides por sementes do algodoeiro em função do período de inoculação das plantas. Summa Phytopathologica, Botucatu, v. 19, n. 3, p. 177-180, 1993.

SUMNER, D. R.; DOWLER, C. C.; JOHNSON, A.W.; BAKER, S. $H$. Conservation tillage and seedling diseases in cotton and soybean double-cropped with triticale. Plant Disease, St. Paul, v. 79, p.372-375, 1995.

VIANELlO, R. L.; ALVES, A. R. Meteorologia básica e aplicações. Viçosa: Imprensa Universitária, 1991. p.395-399.

YOUNG, J. Conservation tillage practices in Louisiana. In: BELTWIDE COTTON CONFERENCE, Orlando, 1995. Proceedings... Memphis: National Cotton Council of America, 1995. 1v.

ZADOCKS, J.C.; SCHEIN, R.D. Epidemiology and plant disease management. Oxford: Oxford University Press, 1979. $427 \mathrm{p}$.

ZANDONADI, B. Algodão no Plantio "Semi Direto" no Mato Grosso. In: CONGRESSO BRASILEIRO DE ALGODÃO, 5., 2005, Salvador. Anais... Salvador, 2005. (CD-Rom) 